BULLETIN Bulletin hispanique

HISPANIQUE Université Michel de Montaigne Bordeaux

109-2 | 2007

La formation du Parnasse espagnol $\mathrm{XV}^{\mathrm{e}}-\mathrm{XVIII}{ }^{\mathrm{e}}$ siècle

\title{
La corona de los prudentes letrados
}

canonizaciones en el siglo XV

Ángel Estévez Molinero

\section{(2) OpenEdition}

Journals

Edición electrónica

URL: http://journals.openedition.org/bulletinhispanique/224

DOI: 10.4000/bulletinhispanique.224

ISSN: 1775-3821

Editor

Presses universitaires de Bordeaux

Edición impresa

Fecha de publicación: 1 diciembre 2007

Paginación: 401-419

ISBN: 978-2-85276-096-7

ISSN: 0007-4640

Referencia electrónica

Ángel Estévez Molinero, "La corona de los prudentes letrados », Bulletin hispanique [En línea],

109-2 | 2007, Publicado el 01 diciembre 2010, consultado el 20 abril 2019. URL : http://

journals.openedition.org/bulletinhispanique/224 ; DOI : 10.4000/bulletinhispanique.224 


\title{
«La corona de los prudentes letrados»: canonizaciones en el siglo XV
}

\author{
Ángel Estévez Molinero \\ Universidad de Córdoba - España
}

Cet article propose une analyse des premiers moments de la construction du Parnasse espagnol, entre les XVE et XVIII siècles. L'amorce in illo tempore, de cette construction est due essentiellement au Marquis de Santillane et à Juan de Mena. Ces deux écrivains utilisent l'allégorie parnassienne en tant qu'espace du couronnement poétique mais ils projettent aussi leur conscience de l'écriture et leur volonté d'ouvrir de nouvelles voies littéraires. La route vers la cime du Parnasse s'achève avec leur canonisation.

El presente artículo analiza la fase inaugural en la construcción de Parnaso español entre los siglos XV y XVIII. El inicio de dicha construcción in illo tempore se debe principalmente al Marqués de Santillana y a Juan de Mena. Estos dos autores utilizan la alegoría parnasiana como espacio para la coronación poética, proyectando su conciencia de la escritura y su voluntad de abrir nuevos caminos literarios. El trayecto hacia la cumbre del Parnaso culmina con su coronación.

This article examines the opening phase in the constitution of the Spanish Parnassus between the $15^{\text {th }}$ and $18^{\text {th }}$ centuries. The beginning of this construction in illo tempore must be mainly attributed to the Marqués de Santillana and to Juan de Mena. These two authors use the Parnassian allegory as the space for a poetic culmination, but also project their literary consciousness and their will to open new literary paths. The journey towards the summit of Parnassus culminates with their canonization.

Mots-clés : Pré-renaissance - Pré-humanisme - Poésie - Parnasse - Canon.

$B H i$, Tome 109, n² 2 - décembre 2007 - p. 401 à 419. 
A

NALIZAR la formación del Parnaso español entre los siglo XV y XVIII presupone aceptar, como punto de partida, que el Parnaso es una construcción in fieri, es decir, algo que se va formando en el devenir temporal y es sometido por ello, en sus elementos constituyentes, a sucesivas visiones y revisiones. De igual modo, entre las diversas opciones que caracterizan paradigmáticamente el concepto, oportunamente desglosadas por Julio Vélez-Sainz, nos interesa retener la del Parnaso como «sistema de producción literaria», con efectos metaliterarios que discriminan selectivamente autores y obras, y como un "motivo de muy alta capacidad alegórica» ${ }^{1}$. En esta perspectiva (y entre otros componentes alegóricos) conviene señalar que «la peregrinación a la cumbre de la montaña simbolizaba la canonización de un poeta» ${ }^{2}$. A partir de estas rápidas consideraciones, para no entretenernos en especulaciones distractoras, asumimos, con Pozuelo Yvancos, la idea de que no existe un canon, sino que hay "cánones diversos, sistemas que se complementan, sustituyen, suplantan. Mejor, sistemas que se han constituido, se han sustituido, se han suplantado" ${ }^{3}$. Cabe deducir que, frente a la concepción ahistoricista del canon, fundamentada en criterios estéticos, preferimos adoptar una perspectiva histórica; nos apoyamos, con palabras de Lía Schwartz, "en la idea de que los cánones, plurales, modelan o reflejan los valores, intereses e ideologías de una sociedad en coyunturas específicas de su desarrollo. Estos van cambiando, pues, a medida que se alteran los conjuntos de normas y convenciones que gobiernan la producción de textos literarios y los grupos que ejercen el poder en una sociedad histórica y sus instituciones culturales» ${ }^{4}$. Es obvio que la encrucijada histórica, cultural y literaria que se vive en la época de Juan II, a mediados del siglo XV, no es la misma que conoce Garcilaso en los tiempos imperiales de Carlos V o Fernando de Herrera en la llamada «edad de la crítica», por limitar la cuestión al siglo XVI.

Parece claro, pues, que el Parnaso y los autores canonizados en su cumbre constituyen un sistema dinámico y, por lo tanto, cambiante; que en el proceso

1. Véase al respecto Julio Vélez-Sainz, El Parnaso español: canon, mecenazgo y propaganda, Madrid, Visor, 2006, pág. 14.

2. Ibid..

3. José María Pozuelo Yvancos, «Canon, ¿estética o pedagogía?», Ínsula, 600 (1996), págs. 3-4 (4). Véase asimismo J. Ma . Pozuelo Yvancos, «El canon en la teoría literaria contemporánea», Eutopías, 108 (1995), págs. 1-40, y J. Ma. Pozuelo Yvancos y Rosa María Aradra Sánchez, Teoría del canon y literatura española, Madrid, Cátedra, 2000, particularmente para el canon y los autores medievales, pág. 189 y ss., así como M. Á. Pérez Priego, «Formación de canon medieval», Ínsula, 600 (1996), pág. 79.

4. Lía Schwartz, «Siglos de Oro: cánones, repertorios, catálogos de autores», Insula, 600 (1996), págs. 9-12 (9). 
de la construcción parnasiana son muchos los que transitan por la laderas del monte y menos los que alcanzan la gloria de una canonización estable. Si la literatura es «un ir y venir entre la historia y la memoria», como decía Francisco Rico en "El tratado general de literatura» ${ }^{5}$, nos parece oportuno e ilustrativo saltar unos buenos y fructíferos tramos de la historia literaria para recuperar, en ejercicio de memoria, algunos momentos significativos que nos remonten a la sincronía objeto de atención, es decir, a mediados del siglo XV; no deja de ser una especie de viaje a la semilla de los Parnasos castellanos inaugurados in illo tempore por Santillana y Mena ${ }^{6}$; o, si se quiere, un descenso por las escaleras del edificio parnasiano hasta lo cimientos sobre los que este se levanta en el terreno literario. Inicio este viaje retrospectivo con un motivo iconográfico, descrito (entre otros) por Pablo de Tarsia, que reproduce el monte Parnaso en el marco de las fiestas que celebraron la llegada a Madrid de Mariana de Austria, segunda esposa de Felipe IV, el día 15 de noviembre de 1649; según lo cuenta Pablo de Tarsia,

Llegó la maravilla al último grado de la esfera, en el monte Parnaso, que con suma magnificencia se hizo sobre la fuente del Olivo; acompañaron las nueve Musas vivas, ricamente tocadas y vestidas, con otras tantas estatuas de Poetas Españoles, muy parecidas a sus originales, que fueron Séneca, Lucano, Marcial, Juan de Mena, Garcilaso de la Vega, Luis de Camoes, Lope de Vega Carpio, don Luis de Góngora y don Francisco de Quevedo ${ }^{7}$.

La descripción recoge, como puede apreciarse, un Parnaso español, selecto y selectivo, condicionado a nueve poetas por el número de las Musas. Un año antes, la edición de la poesía quevediana editada por González de Salas aparece adornada con un grabado en que puede verse, en la parte inferior derecha del inframundo, un retrato del autor (¿o su rostro reflejado en un espejo?) en posición frontal, legitimado como tal por la vera efigies reproducida; en el mismo plano, a la izquierda, se hace mención expresa

5. Francisco Rico, Primera cuarentena y Tratado general de literatura, Barcelona, Quaderns Crema, 1982, pág. 141.

6. Es a todas luces esclarecedor, e imprescindible en tantos aspectos, el ya clásico estudio de Ma . Rosa Lida, Juan de Mena, poeta del Prerrenacimiento español, México, El Colegio de México, 1984 (2a ed.). Véase asimismo Guillermo Serés, «Juan de Mena y el «Prerrenacimiento», estudio preliminar a Juan de Mena, Laberinto de fortuna y otros poemas, ed. Carla de Nigris, Barcelona, Crítica, 1994, y Vicente Beltrán, «La encrucijada de Santillana», estudio preliminar a Marqués de Santillana, Comedieta de Ponza, sonetos, serranillas y otras obras, ed. Régula Rohland de Langbehn, Barcelona, Crítica, 1997.

7. Pablo A. de Tarsia, Vida de D. Francisco de Quevedo [1663], edición facsímil, Cuenca, Universidad de Castilla-La Mancha, 1997, fol. 27v. 
a las nueve musas; sobre este plano, a la espalda del autor (o frente a él, si aceptamos la imagen especular) se reproduce la alegoría parnasiana con el monte en dos cumbres dividido y Pegaso en una de sus laderas, al fondo; a la izquierda, las nueve musas contemplando la escena y, a la derecha, Apolo dispuesto a colocar sobre la cabeza del autor, convertido ahora en personaje del Parnaso, la corona de laurel. No hay dudas sobre la excelencia de los nueve poetas representados en la iconografía de Pablo de Tarsia ni, claro está, sobre la de Quevedo, ya incluido en aquélla; como tampoco se pone en duda la presencia de Góngora, cuyo retrato (remedo fácilmente reconocible del realizado por Velázquez) portica en 1630 las Lecciones solemnes de Pellicer junto a un ángel trompetero que pregona su fama mientras una corona de laurel se suspende sobre su cabeza. Pero ya por entonces los criterios para laurear se habían relajado tanto que, en 1634, por boca de Burguillos (cuyo retrato, remedo tosco del de Lope, denuncia su condición de heterónimo), el Fénix ironizará «sobre la estimación que se hace en este tiempo de los laureles poéticos», cargando contra «la importuna infantería / de poetas fantásticos noveles» que pedían "por principios más laureles / que anima Dafnes y que Apolo cría. / Pedíle yo también por estudiante, / y díjome un bedel «Burguillos, quedo: / que no sois digno de laurel triunfante». / «iPor qué?», le dije, y respondió sin miedo: / «Porque los lleva todos un tratante / para hacer escabeches en Laredo» ${ }^{8}$. La devaluación de los laureles, la relajación de las patentes parnasianas y consiguientemente de los certificados canónicos ya habían sido puestas en solfa con anterioridad en ese viaje de ida y vuelta, satírico y desmitificador, que es el Viaje del Parnaso ${ }^{9}$. ¡Qué distinta la actitud aquí proyectada por Cervantes de la mostrada, unos treinta años antes, en el Canto de Caliope!

Por la mente de cualquier seguidor atento de la historia literaria cruzarán otros muchos ejemplos de conformaciones parnasianas y sanciones canónicas, de Espinosa y Herrera a Garcilaso, de Valdés a Encina y Nebrija. Y en el origen, movilizando la formación de Parnaso, en esa encrucijada en que confluyen el otoño de la Edad Media y el Prerrenacimiento, el mundo que declina y el que comienza a nacer, nos encontramos con Santillana, Mena y, a mayor distancia, Gómez Manrique con una posición distinta a la que adoptarán un siglo después Boscán y Garcilaso; como también será distinta

8. Lope de Vega, Obras completas. Poesía, II: Rimas. Rimas sacras. Rimas humanas y divinas del licenciado Tomé de Burguillos, ed. de Antonio Carreńo, Madrid, Biblioteca Castro, 2003, pág. 555.

9. Véase al respecto Pedro Ruiz Pérez, «El Parnaso se desplaza: entre el autor y el canon», en Begońa López Bueno (ed.), En torno al canon: aproximaciones y estrategias, Universidad de Sevilla, 2005, págs. 197-232. 
la de Herrera, en la llamada edad de la crítica ${ }^{10}$, respecto al toledano, o la del Cervantes desencantado respecto a Herrera, o la de Gracián y Saavedra Fajardo respecto a Cervantes, etc. Son sincronías ciertamente distintas, pero que no se niegan diacrónicamente, sino que se prolongan; hace ya ańos Pierre le Gentil advertía que el siglo XVI no debe imponer la imagen que él se ha forjado del mundo medieval, porque sólo ha conocido el final de este mundo, del que el Renacimiento se propone como antítesis, pero que en realidad continúa ${ }^{11}$. Verdad es que estos poetas del reinado de Juan II, por carecer de formas, se contentaban con las materias; que por ello, extendiendo lo que Francisco Rico apuntó sobre Santillana, ejemplifican «el drama del prehumanismo español; la tragicomedia de una élite de curiales y nobles deslumbrados por la cultura de moda en Italia e incapaces de seguirla (o aun de comprender de qué iba en realidad) por haberse criado a pechos de una tradición intelectual enteramente distinta» ${ }^{12}$. Pero no es menos cierto que favorecen la recepción y asimilación del humanismo y el advenimiento de las innovaciones renacentistas; pero ello, acaso proceda valorar en sus justos términos, de acuerdo con la fase de historización que viven, ese deslumbramiento novedoso ante el sistema cultural, impregnado de clasicismo, que proviene de Italia, básicamente de las obras (también básicamente latinas) de Dante, Petrarca y Boccaccio. A fin de cuentas, como avisa el Marqués en su Proemio e carta, apoyándose en el filósofo, "de los primeros, primera es la especulaçión» ${ }^{13}$, que es tanto como advertir que el comienzo de un proceso es el principio de una mejora progresiva a partir de las carencias que le son consustancialmente propias. Añádase a ello, con cierta percepción de encrucijada, la actitud de humildad que denotan los

10. Pues «los contemporáneos de Herrera habían ganado maestría y doctrina respecto a los contemporáneos de Garcilaso», como indica Francisco Rico, «El destierro del verso agudo (Con unas notas sobre rimas y razones en la poesía del Renacimiento", en Homenaje a José Manuel Blecua, Madrid, Gredos, 1983, págs. 515-551 (544). Puede verse asimismo Ángel Estévez Molinero, «Los descuidos de Garcilaso en la perspectiva crítica de Herrera (Con algunas notas sobre las necedades en las Anotaciones»), en Begońa López Bueno (ed.), Las "Anotaciones» de Fernando de Herrera. Doce estudios, Universidad de Sevilla, 1997, págs. 135-156.

11. Cfr. Pierre Le Gentil, La poésie lyrique espagnole et portugaise à la fin du Moyen Age, Rennes, Plihon, 1949-1952.

12. Francisco Rico, «El quiero y no puedo de Santillana», en Primera cuarentena, op. cit., pág. 33. La cuestión queda profusamente documentada en el excelente estudio de Guillermo Serés, "La autoridad literaria: círculos intelectuales y géneros en la Castilla del siglo XV», incluido en este volumen.

13. Marqués de Santillana, Poesías completas, ed. Maxim P. A. M. Kerkhof y Ángel Gómez Moreno, Madrid, Castalia, 2003, pág. 649; la referencia al filósofo remite a Aristóteles y su tratado de Física. 
diminutivos de títulos como Comedieta y Triunfete respecto a la Comedia dantesca y los Triunphi de Petrarca.

Ahora bien, sin perder la referencia de que esa franja de mitad del siglo $\mathrm{XV}$ es una zona fronteriza ( $\mathrm{y}$, como toda frontera, punto de encuentro, conflicto y contagio humano), puede fácilmente percibirse que el sistema literario se está moviendo, porque también se está moviendo el sistema cultural que lo sustenta. Santillana es consciente (en la medida que puede serlo) de su participación activa en el ensanchamiento de la cosmovisión humana que está teniendo lugar; así lo manifiesta, con orgullo de precursor, en la carta dirigida a su hijo para que traduzca la Ilíada: "A ruego e instançia mía, primero que de otro alguno, se han vulgarizado en este reino algunos poetas...», entre los que cita a Virgilio, Ovidio, Séneca el trágico... y ahora (pues tal es la petición que hace a su hijo) a Homero, príncipe de todos ellos.

Precisamente el empleo del término 'poeta' refleja en algún sentido (y con las vacilaciones comprensibles) la conciencia de esa situación cambiante. Según los datos registrados en el CORDE, Santillana utiliza el término diecinueve veces en singular y veintitrés en plural; Mena, doce y cincuenta y dos, respectivamente. Pasando de lo cuantitativo a la cualitativo, la designación de la categoría de poeta, en singular, hecha por Santillana se antoja ilustrativa; en seis ocasiones la refiere a Boccaccio, adjetivado de excelente, ilustre y moderno; tres, a Homero (soberano en dos de ellas); dos a Petrarca, en ambas laureado; una, respectivamente, a Horacio, Sátiro y Gómez Manrique (en este caso, por encarecimiento indirecto en respuesta al sobrino); tres veces usa el término de manera genérica; de los dos casos restantes, en uno se refiere a Alain Chartier como «muy claro poeta moderno" (lo que puede justificarse a la luz valorativa que hace en el Proemio de la tradición provenzal) y en el otro, de manera más admirativa, a Micer Francisco Imperial, sin duda por considerarlo un autor próximo a los valores de la poesía italiana, la más estimada de las lenguas vulgares; dice a propósito de Imperial que "yo no lo llamaría decidor o trobador mas poeta, commo sea çierto que, si alguno en estas partes del occaso mereçió premio de aquella triunphal e láurea guirnalda, loando a todos los otros, éste fue» ${ }^{14}$; y ya tenemos, por efecto de la laureación, la coronación. Pero lo importante es que Santillana privilegia, frente al decidor y al trobador, al poeta. Vale recordar, al respecto, que Quintiliano y Dante reservan la categoría de poeta para los grandes autores frente a la condición de versificator (Quintiliano) o dicitori y rimatori (Dante). ¿Por qué no inferir que en la Castilla del siglo XV

14. Id., pág. 657. 
opera dicha distinción y que son rasgos definitorios del poeta su prestigio, unido a su capacidad de liderazgo, su altura y su excelencia? En cualquier caso, con el término de "poeta" aún en fase de aclimatación a la poesía española, Santillana está mostrando su admiración por Imperial, que había tenido como modelo a Dante.

No las recoge el CORDE en el caso de Santillana (sí en el de Mena), pero en las preguntas y respuestas que uno y otro se entrecruzan, aquél concede en tres ocasiones al cordobés la categoría de poeta. Conviene insistir en ello; y voy a hacerlo a propósito de los intercambios y la promoción subsiguiente que se hacen entre sí Santillana y Mena (en menor medida Gómez Manrique), actitud que debe relacionarse con la creación de un Parnaso castellano. En tal sentido, según indica Vélez-Sainz, «los dos autores utilizan el motivo conscientemente para representar la formación de un sistema literario. El Parnaso codificó el intercambio de poemas entre uno y otro, de tal manera que ambos procuran, siguiendo el ejemplo de los autores del trescientos italiano, la creación de un Parnaso moderno castellano» ${ }^{15}$. En efecto, en el intercambio poético que Santillana mantiene con el cordobés lo llama "poeta de Mena» ${ }^{16}$, lo califica de excelente ${ }^{17}$ y famoso ${ }^{18}$, y lo equipara en una de sus respuestas a Homero, Virgilio y Lucano:

$$
\begin{aligned}
& \text { La vuestra eloqüençia es fuente que mana } \\
& \text { dulçura de metros e nunca retroga, } \\
& \text { la mi obra çía e la vuestra boga } \\
& \text { por los altos mares con gloria mundana. } \\
& \text { E si la mi pluma la verdat explana, } \\
& \text { yo non dudaría que presto serés } \\
& \text { méritamente igual que los tres } \\
& \text { que en la poesía son lunbre diafana }{ }^{19} \text {. }
\end{aligned}
$$

Mena, a su vez, concede a Santillana el certificado de la inmortalidad, pues

Por vuestras vigilias e grand fructo d'ellas, todos los siglos vos serán en cargo;

fallarlas han siempre sin ningund embargo, de mortalidad esentas aquéllas ${ }^{20}$,

15. Julio Vélez-Sainz, El Parnaso español: canon, mecenazgo y propaganda, op. cit., pág. 53.

16. Marqués de Santillana, Poesías completas, op. cit., pág. 590.

17. Id., pág. 588.

18. Id., pág. 592, si bien en este caso la calificación se recoge en la rúbrica: «Pregunta que fizo el señor Marqués de Santillana al famoso poeta Juan de Mena».

19. Id., pág. 591; los tres poetas implicados, según deducen Kerkhof y Gómez Moreno a la luz de la copla XXII de la Coronación de mossén Jordi de Sant Jordi, son mencionados arriba.

20. Id., pág. 586. 
además de encumbrarlo en el Parnaso, doblemente coronado de laurel y ramas de encina, en La coronación. Por su parte, Gómez Manrique, espoleado por el entusiasmo de los vínculos familiares y por su condición de discípulo, considera que el Marqués es «de los sabios el más eçelente / e de los poetas mayor que Lucano» ${ }^{21}$, asegurando con la emotividad propia del planto que dedica a su muerte que "en los metros el Dante / ant'él se mostrara neçio»" En este mismo planto, también Gómez Manrique elogia a Juan de Mena, muerto dos años antes, por boca de la Poesía:

Esta muerte que condena
a buenos e comunales
me leuó a Juan de Mena
cuya pluma fue tan buena
que vi pocas sus yguales ${ }^{23}$.

Pero donde mejor se aprecia la voluntad de canonización (de autocanonización incluso) es en aquellos poemas en que se utiliza explícitamente la alegoría parnasiana o se diseminan, con un empleo más restrictivo, los motivos parnasianos. A partir de obras como la Coronación de mossén Jordi de Sant Jordi, el Infierno de los enamorados, la Defunsión de don Enrique de Villena y la Comedieta de Ponza, en el caso de Santillana, y la Coronación del Marqués, el Claro escuro y el Laberinto, en el de Mena, destacaremos algunos aspectos que apuntan, en la intersección de Edad Media y Renacimiento, a la formación de un nuevo sistema literario, a la conformación de un Parnaso castellano y, resultativamente, a la canonización de los autores objeto de referencia así como, sobre todo, de los propios poetas implicados en esa construcción. Digamos, de salida, que es fácil apreciar en todas estas obras la alegoría parnasiana o, en su defecto, motivos parnasianos concretos. Puede servir de ejemplo la copla II del Infierno:

\author{
¡Oh vos, Musas, qu’en Parnaso \\ fazedes habitación \\ allí don fizo Pegasso \\ la fuente de perffecçión! \\ En el fin e concluçión,
}

21. Gómez Manrique, Cancionero, ed. Francisco Vidal González, Madrid, Cátedra, 2003, pág. 207.

22. Id., pág. 409.

23. Id., pág. 402. 


$$
\begin{aligned}
& \text { en el medio e començando, } \\
& \text { vuestro subsidio demando } \\
& \text { en esta proposiçión }{ }^{24} \text {. }
\end{aligned}
$$

Además de los elementos parnasianos referidos (monte, Musas, Pegaso, fuente), hay que destacar la invocatio múltiple que se anticipa, inscrita en la tradición inaugurada por Quintiliano. Hasta en cinco ocasiones invocará Santillana a las Musas en la Comedieta; así puede ya verse en la copla II tras apelar, en primer lugar, a Júpiter:

¡O lúcido Jove, la mi mano guía, despierta el ingenio, abiva la mente, el rústico modo aparta e desvía, e torna mi lengua, de ruda, elocuente!

¡E vos, las hermanas que cabe la fuente de Helicón fazedes continua morada, sed todas conmigo en esta jornada, porqu'el triste caso denunçie e recuente! ${ }^{25}$.

Esta invocatio múltiple se reafirma en las coplas IX («Pues fabla tú, Çirra e Nissa responda, / en el rudo pecho exortando a pleno; dissuelva Polimia la cuerda a la sonda, / ca fondo es el lago e baxo el terreno»), LXXXIV («Aquí Caliope, Melpómene e Clío / e las otras musas, pues voy comediando, / dad remos e velas al flaco navío...»), XCIV («i O Musas, mostradme las gentes insignes...») y CI («otorgadme, Musas, que en metro elevado / recuente las reinas e donas de estado...») ${ }^{26}$.

Algunas derivaciones, a grandes trazos, pueden extraerse de los ejemplos referidos; por una parte, junto a las reflexiones metapoéticas sobre la adecuación de materia y estilo, la invocación trasluce la conciencia escritural del poeta; tales invocaciones, por otra parte, se antojan impensables en una obra de carácter cristiano o ideológicamente cristianizada; el contraste con los poemas que seguidamente proponemos refuerza esta idea. Así, por ejemplo, en el planto que Gómez Manrique dedica a su tío, el Marqués, condicionado sin duda por una actitud cristiana de base teocéntrica, proclama al comienzo que no invocará a los planetas ni a las Musas, ni a Venus, sino a Cristo:

\footnotetext{
Non inuoco las planetas que me fagan elocuente; non las çirras muncho netas
}

24. Marqués de Santillana, Poesía completas, op. cit., pág. 259.

25. Id., págs. 295-96

26. Id., págs. 299-300, 337, 341 y 346, respectivamente. 


\author{
nin las hermanas discretas \\ que moran cabe la fuente; \\ ni quiero ser socorrido \\ de la madre de Cupido, \\ nin de la Tesalïana, \\ mas del nieto de Sant'Ana \\ con su saber infynido ${ }^{27}$.
}

Aunque el modelo inmediato, si bien corticalmente asimilado, es la copla II de la Comedieta (supra reproducida), poco demuestra haber aprendido Gómez Manrique de su maestro sobre las nuevas actitudes con respecto a la vida y la literatura. Más de veinte años atrás, Santillana había escrito la Defunsión de don Enrique de Villena, muerto en 1434; en la segunda copla de arte mayor, advierte el Marqués que los poetas, según sea la materia, suelen invocar a Apolo, Cupido y Venus, Júpiter, Marte o las Musas, «mas yo a ti (es decir, al difunto Villena) sólo me plaze llamar, / joh cíthara dulce más que la d'Orfeo", proclama en la copla III ${ }^{28}$; seguidamente (coplas IV y V), el sujeto lírico, a su vez personaje bajo la imagen del homo viator, da cuenta de su peregrinación por un camino no transitado (que implica al tiempo un cursus o carrera literaria) hasta conseguir, a la altura de la copla XVII, llegar a la cima del monte «no menos cansado que Dante [a] Aqueronte» ${ }^{29}$; allí (copla XVIII) encuentra a "nueve donzellas en torno plañiendo" ${ }^{30}$, las cuales lamentan haber perdido con anterioridad a Homero ("que mucho honorava / este sacro monte do nos habitamos» ${ }^{31}$ ), a Ovidio («al qual coronamos / del árbol laureo» ${ }^{32}$ ), a Horacio («que nos invocava / en todos exordios de su poesía» ${ }^{33}$ ), a Tito Livio, Virgilio, Salustio, Lucano, Terencio, Dante, Petrarca, etc., hasta llegar a don Enrique de Villena (copla XXI) que metonímicamente, es decir, por efecto de la contigüidad con los autores mencionados, queda canonizado como el mayor de «los sabios del tiempo presente» ${ }^{34}$; la voz lamentable, por su parte, confiesa que «de dolor pungido, lloré tristemente / e maldixe Antropos, con furia indignado» ${ }^{35}$. Lo más destacable y llamativo, en el marco de un poema elegiaco del siglo XV

27. Gómez Manrique, Cancionero, op. cit., págs. 367-68. Así vuelve a reafirmarse en la copla XXXIV: «al mayor de los mayores / inuoco que me prouea» (pág. 380).

28. Marqués de Santillana, Poesías completas, op. cit., págs. 285-86.

29. Id., pág. 292.

30. Ibid..

31. Id., pág. 293.

32. Ibid..

33. Ibid.

34. Id., pág. 294

35. Ibid.. 
-y contrástese con la actitud que mostrará años después Gómez Manrique al llorar a su tío (muerto en 1458)-, es que no hay atisbo alguno de consolatio cristiana; la voz lamentable es solidaria en su dolor con el lamento de las musas plañideras a las que encuentra, luego de su pesarosa escalada, en el Parnaso; y la descarga emotiva final es la imprecación contra Átropos por haber cortado a don Enrique el hilo de la vida que Cloto había tejido.

Otro aspecto en el que conviene insistir es la imagen del homo viator en que el autor se autocontempla para dar cuenta de su peregrinación por un camino no transitado, que implica un cursus o carrera literaria; esta idea conlleva la conciencia autorial de estar desplazándose hacia un nuevo sistema cultural y literario; por lo mismo, el sujeto lírico que ha llegado en su peregrinaje a la cumbre del monte, encumbra a su vez, por efecto de la contigüidad con la voz lamentable, al poeta que lo sustenta, es decir, al Marqués de Santillana. Algo similar puede apreciarse en otras de las obras mencionadas; así ocurre, por ejemplo, en el Infierno (sálvese la lección moral que emana de los castigos presenciados) de manera que, en este caso, «Santillana refuerza, de nuevo, la influencia de Boccaccio y Petrarca como creadores de un Parnaso nacional centrado en la lírica amorosa»; según señala Vélez-Sainz ${ }^{36}$.

Una lectura parecida, con la mediatización que impone la hendíadis cultural y programática, cabe hacer del Claro-escuro. La primera estrofa, en arte mayor, describe el amanecer mitológico con el carro del sol recorriendo los doces signos del zodiaco:

\author{
El sol claresçía los montes Acayos, \\ los vales de Creta e torres de Baco, \\ por nuestro emisperio tendiendo sus rayos, \\ el viso de Venus faziendo más flaco. \\ El cual reportava fondón del sobaco \\ las ruedas del carro do manso leyendo \\ por cursos medidos andava corriendo \\ las doze señales del grand zodïaco ${ }^{37}$.
}

36. Julio Vélez-Sainz, El Parnaso español: canon, mecenazgo y propaganda en la poesía de Siglo de Oro, op. cit, pág. 55; en esta misma página, según precisa el autor, "Santilla presenta una carrera literaria que combina el modelo dantesco con el tema amatorio parnasiano que iniciaran Boccaccio y Petrarca posteriormente. La deuda de Santillana y Mena con Boccaccio y Petrarca es explícita y también está expresada en términos parnasianos. En la Comedieta de Ponza (1444) Santillana corona a Boccaccio (v. 76), aunque exclama que Petrarca debe estar laureado por encima de todos (239). La laureación de ambos tiene todo el sentido pues toma de Petrarca la estructura de Triunfo que tiene su fantasía moral en cuanto descripción de gente famosa (grandes reyes y reinas, poetas, guerreros). De Boccaccio toma las descripciones de varones y mujeres ilustres, lo que ejemplifica el mismo Boccaccio como personaje».

37. Juan de Mena, «Laberinto de fortuna» y otros poemas, ed. Carla de Nigris con estudio 
Sigue otra estrofa, ahora en arte menor con dos versos quebrados, con los tópicos juegos conceptuosos por contraposiciones, repeticiones y derivaciones léxicas, que enmarca la no menos tópica situación del mal de amores:

\footnotetext{
Quando vi morir mi vida

e vida dar a mis males, cuya vida es despedida

de quien fue descognosçida

a mis penas desiguales,

entonces bien me pensé,

pensé que el mi pensamiento

tanto fuerte

non toviera sobre qué,

sobre qué darme tormento

sobre muerte ${ }^{38}$.
}

Si ya estas dos primeras estrofas del poema reflejan la encrucijada cultural, lingüística y literaria en que Mena se debate, casi hacia el final manifiesta el trabajoso afán de transitar por un camino, desconocido en términos retóricoestilísticos, que le conduzca a la fama eterna:

\footnotetext{
Non me conmueve la grand disciplina de la poesía moderna abusiva, nin ove bebido la limpha divina, fuente de Phebo, muy admirativa; nin sope el camino por qué lugar iva la senda Safos en el monte Parnasso; mas causa me mueve del daño que passo, que fuerças y seso y bienes me priva ${ }^{39}$.
}

El cordobés declara, en esta curiosa referencia al Parnaso, no haber bebido la inspiración que procuran las aguas la fuente Castalia y desconocer el camino que condujo a Safo hasta la cumbre de la fama eterna, con lo que proclama así su independencia literaria, a la manera de los antiguos romanos (Lucrecio, Nemesiano...), sugiriendo que su poesía discurre por un camino nuevo. Se explicita de este modo un proceso de búsqueda en el que se implica la imagen del homo viator (caminar poetizando por donde nadie lo ha hecho); esa búsqueda se proyecta especularmente desde el título, Claro escuro, oscilante entre la claridad (a la manera cancioneril) con que fluye la temática amorosa por el cauce del arte menor y la oscuridad derivada

preliminar de Guillermo Serés, op. cit., pág. 22.

38. Id., págs. 22-23.

39. Id., pág. 28. 
del acarreo erudito y clásico en el molde del arte mayor. El estímulo de una amada-musa podría facilitar, por la senda de la moderna poesía, el ascenso al Parnaso y a la fama que se afana en conseguir.

Pero donde la alegoría parnasiana presenta un diseño más nítido y elaborado es en aquellas composiciones que Santillana y Mena dirigieron «a amigos a quienes esperaban canonizar por medio de la palabra poética. Es tan interesante a quién canonizan -advierte Vélez-Sainz- como donde lo hacen» ${ }^{40}$. Santillana trasluce una cierta fascinación por mosén Jordi, a quien había conocido en la corte de Fernando de Antequera; dice de él en el Proemio: «En estos nuestros tiempos floresçió mosén Jorde de Sant Jorde, cavallero prudente, el qual çiertamente conpuso asaz fermosas cosas, las quales él mesmo asonava ca fue músico exçellente» ${ }^{41}$. A él dedica la Coronación de mossén Jordi de sant Jordi ${ }^{42}$, que comienza con un amanecer mitológico, a imitación de Dante (Purgatorio, IX), de quien toma asimismo el motivo del somnium ${ }^{43}$, que sirve para enmarcar un escenario ameno por el que viene un grupo de doncellas entre las que destaca una que por «su filosofía / e forma non era humana» (vv. 53-54) ${ }^{44}$, que resulta ser Venus. «Bolví al siniestro lado / e vi tres magnos varones» (vv. 89-90) y, delante

40. Julio Vélez-Sainz, El Parnaso español: canon, mecenazgo y propaganda en la poesía de Siglo de Oro, op. cit, pág. 56.

41. Marqués de Santillana, Poesías completas, op. cit., págs. 652. «Solo un efecto de fascinación parece explicar que el Marqués trasmudara un trovador en poeta, presentándolo en la Coronación al lado de Homero, Virgilio y Lucano, bajo la sombra de Dante», indica Lluis Cabré, «Notas sobre la memoria de Santillana y los poetas de la corona de Aragón», en 'Cancionero'. Studies in Honour of Ian Macpherson, ed. Alan Deyermond, Londres, Queen Mary and Westfield Collage, 1998, págs. 25-38 (29).

42. Según Rafael Lapesa, La obra literaria del Marqués de Santillana, Madrid, Ínsula, 1957, pág. 111, «tejida de tópicos librescos y con fuerte latinismo en lenguaje, la Coronación no pierde por eso el encanto de la facilidad: los versos fluyen con soltura y la riente gracia de Venus parece trasfundida en muchos de ellos. Fue el primer modelo de panegírico en la poesía de Castilla y no tuvo par hasta que otro poeta, Juan de Mena, celebró a Santillana siguiendo sus propias huellas».

43. Siguiendo a Rafael Lapesa, op. cit., quien destaca asimismo la influencia de Virgilio, Eneida, canto IV, v. 60 y ss., así lo recuerdan Maxim P. A. M Kerkhof y Ángel Gómez Moreno en su introducción a Marqués de Santillana, Poesías completas, op. cit., pág. 38. Para la influencia de Dante en el Marqués, véase Joseph A. Seronde, «Dante and the french influence on the Marqués de Santillana», The Romanic Review, 7 (1916), págs, 194-210, así como Alvin H. Pianca, «Influencias dantescas en la obra del Marqués de Santillana», Estudios, 69 (1965), págs. 263-272. El sentido de la Coronación es puesto por Julio Vélez-Sainz, op. cit., en relación con el Trattattello in laude di Dante, de Boccaccio, y con los Triumphi de Petrarca.

44. Citamos por Marqués de Santillana, Poesías completas, op. cit., pág. 215 y ss., indicando entre paréntesis los versos correspondientes. 
de las doncellas, un caballero «que me paresçía / en la loqüela estrangero» (vv. 103-104); aquellos tres grandes varones - «El gran eloquente / Homero, el Mantuano / e yo terçero, Lucano» (vv. 173-75)- se dirigen a la diosa:

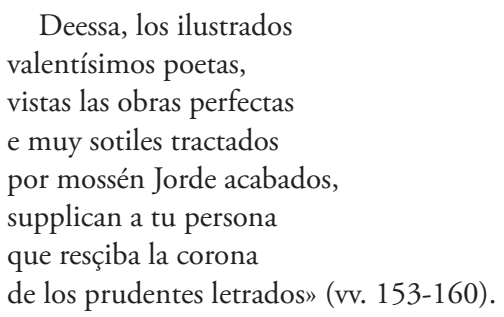

\section{Señala al respecto Vélez-Sainz:}

Santillana relaciona a Mosén Jordi con una genealogía que incluye a todos los grandes poetas heroicos del canon occidental: Homero, Virgilio, Lucano y Dante. Es destacable que, de todos lo presentes, se le ofrezca la palabra a Lucano, el poeta local con el que Santillana tiene más en común. Finalmente, es igualmente interesante que sea Venus quien otorga el laurel, diosa poco apropiada para la tarea, lo que apunta a la constitución del modelo de poesía erótico-parnasiana que desarrollaran Boccaccio y Petrarca ${ }^{45}$.

Siguiendo la estela del panegírico que don Iñigo López de Mendoza dirige a mosén Jordi, Juan de Mena escribirá La coronación del Marqués de Santillana, que es, en opinión de Vélez-Sainz, «el texto más interesante desde el punto de vista parnasiano de todo el siglo XV» ${ }^{46}$. La composición, en coplas reales, comienza con la descripción del amanecer mitológico y, tras ella, se nos presenta al poeta mediante la imagen del homo viator «en una selva muy brava / de bosques thessalianos, / ignotos a los humanos, / yo, que solo caminava» (copla II) ${ }^{47}$. La razón del camino emprendido es, a imitación de Safo, alcanzar la cumbre del monte, es decir, la fama, de lo que se cree incapaz en el Claro escuro:

La causa de mi camino fue clamor de la gran fama que de aquel monte divino,

45. Julio Vélez-Sainz, El Parnaso español: canon, mecenazgo y propaganda en la poesía de Siglo de Oro, op. cit, pág. 56.

46. Ibid..

47. En el caso de la Coronación, citamos por Juan de Mena, Obra completa, ed. de Ángel Gómez Moreno y Teresa Jiménez Calvante, Madrid, Turner, Biblioteca Castro, 1994, pág. 177 y ss., indicando entre paréntesis, la copla correspondiente. 
do Sapho lesbia pervino, por muy muchos se derrama (copla, III) ${ }^{48}$.

Ese camino hacia el Parnaso implica un proceso de búsqueda escritural realizado con evidente esfuerzo ("yo, que solo caminava») y con la voluntad de construir un nuevo sistema literario. La intitulación de Calamicleos (miseria y gloria) ${ }^{49}$ parece sugerir, desde el título, como en el caso de Claro escuro, la hendíadis cultural y programática que bien puede tomarse, como hace Guillermo Serés, "para caracterizar simbólicamente un periodo, el Prerrenacimiento, en el que para compensar la falta de eloquentia clásica (o para emularla) y escaso conocimiento del significado real de la Antigüedad se opta muchas veces por encarar complementariamente latinismos y casticismos, ejemplos tradicionales y antiguos, géneros medievales y erudición o elocución clasicistas» ${ }^{50}$. Ahora bien, mientras en el Claro escuro el trato escritural dado a los términos opera por yuxtaposición paradigmática, en Calamicleos se privilegia la dispositio sintagmática que transita de la miseria (y la moralidad) a la gloria (y la coronación); es decir, se progresa hacia la construcción parnasiana.

La estructura se enmarca entre una introducción (localización temporal y espacial, y declaración de la causa que orienta el camino) y una conclusión (petición a la Fama que pregone la coronación del Marqués entre los más célebres sabios y virtuosos de la Antigüedad pagana y cristiana). En medio se organizan dos partes (coplas IV-XXIV y XXV-XLVIII) en que se oponen dos espacios (el valle de Tesalia y el monte Parnaso), dos acciones (descenso y ascenso), dos actitudes (el pecado y la sabiduría) y dos recompensas (el castigo y la beatitud), según ha señalado Pérez Priego ${ }^{51}$. Sobrepasada la

48. Según Vélez-Sainz, El Parnaso español: canon, mecenazgo y propaganda en la poesía de Siglo de Oro, op. cit, pág. 56, "Mena hace una referencia doble a Safo (la décima Musa) y a Boccaccio quien describió la ascensión de Safo en De mulieribus claris (1369), de donde tomó la referencia Mena».

49. El Brocense, simplificando el preámbulo primero de Mena, anota lo siguiente: «Intituló el poeta esta obra Calamicleos, componiendo el vocablo de calamitas, nombre latino que significa "miseria», y de cleos, que en griego quiere dezir "gloria». Todo junto quiere dezir "tratado de miseria y gloria», porque, fingiendo el poeta que un tiempo, siendo arrebatado para en el monte Parnaso ver coronar al Marqués de Santillana entre los excelentes poetas, passó el valle de miserias, donde vio los tormentos de los dańados. Ansí que trata en estas cinquenta coplas [en realidad son cincuenta y una] de la miseria de los malos y de la gloria de los buenos, porque un contrario, puesto cabe otro, más reluzga», en Juan de Mena, Obra completa, ed. Ángel Gómez Moreno y Teresa Jiménez Calvante, op. cit., pág. 177.

50. Guillermo Serés, en estudio preliminar a Juan de Mena, "Laberinto de fortuna» y otros poemas, ed. Carla de Nigris, op. cit., pág. xxxii.

51. Miguel Ángel Pérez Priego, introducción a Juan de Mena, Obras completas, Barcelona, 
mitad del poema, en el tránsito de la miseria a la gloria, cuando ya el poeta se encuentra a las faldas del monte Parnaso, solicita la inspiración necesaria que alumbre sus versos, invocando a Orfeo:

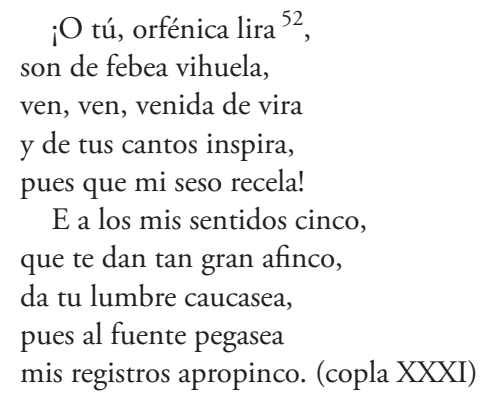

Anticipa a continuación que referirá aquellos «antecesores» destacados "por sus hechos estremados / e muy grandes maravillas / en aquel rengle de sillas / que da vida en los passados» (copla XXXII) y describe en las tres coplas siguientes el monte Parnaso donde se asientan Salomón, David y Aristóteles (copla XXXVI); continúa con autores de la antigüedad grecolatina, aprovechando para destacar sus raíces cordobesas:

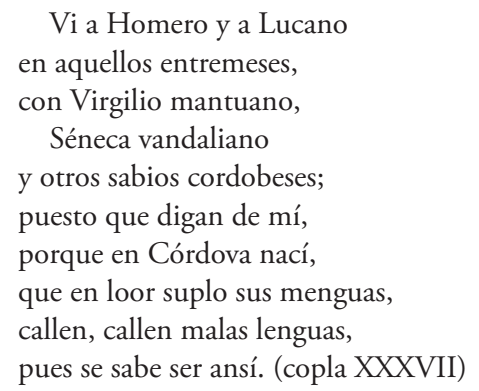

Planeta, 1989, págs. XVII-XVIII.

52. Con respecto al empleo de este mito, indica Pilar Berrio Martín-Retortillo, en «Orfeo en la Coronación de Juan de Mena», DICENDA. Cuadernos de Filología Hispánica, 14 (1996), págs. 21-46: «En una alegoría puramente medieval, de una moralidad poco esperanzada, en absoluto parece que Mena haya asimilado la concepción del mito, que se apuntaba en Petrarca, Coloccio Salutati y Boccaccio, como defensa de la poesía. Tampoco se observa que nos haga pensar en el Orfeo "priscus theologus», uno de aquellos sabios de la Antigüedad que recibieron parte de la Revelación divina para transmitirla a la Humanidad, que se fraguó al calor del círculo neoplatónico de Florencia» (46). No obstante, la invocación a un personaje pagano, entendemos, no debe pasar desapercibida, como tampoco su vinculación a la inspiración poética. 
La relación de "prudentes autores» se completa con Ovidio, Vegecio y Boecio y se cierra con la relación de las nueve Musas, a una de las cuales se dirige el sujeto lírico con ánimo de satisfacer su curiosidad:

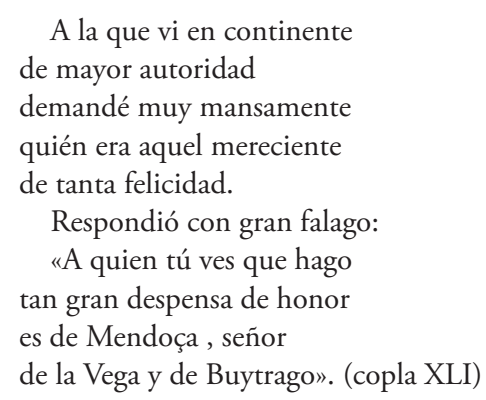

Tras el intercambio de información,

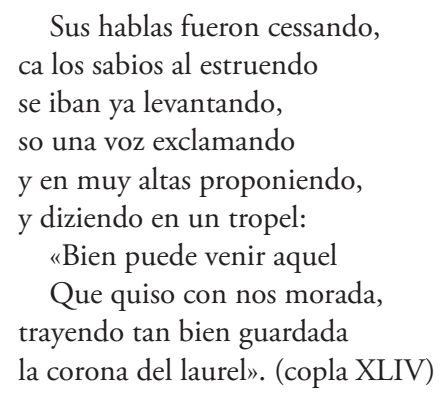

El reconocimiento al Marqués de Santillana se ve reforzado al añadir a la corona de laurel propuesta por los sabios la que le conceden las cuatro virtudes cardinales, que «A las otras excedía, / pues que sin ser laureada / era su follagería / de ramos y valentía / de robles ramificada» (copla XLVII). El ritual culmina con la petición del autor a la Fama para que pregone la coronación, "pues que te mandan que seas / desta fiesta pregonera» (copla XLIX). «Excedía esta corona a las del laurel, porque siendo de roble significa corona de caballería y fortaleza», según anota el Brocense simplificando el comentario de Mena ${ }^{53}$. La doble corona, de laurel y roble, armoniza en el marco de la Coronación del Marqués de Santillana el clásico topos de la fortitudo et sapientia que, en el contexto prerrenacentista en que se inscribe la obra del cordobés, invita a realizar algunas reflexiones.

53. En Juan de Mena, Obra completa, ed. Ángel Gómez Moreno y Teresa Jiménez Calvante, op. cit., pág. 200. 
Hace ya tiempo, como resumimos más arriba, advertía Pierre le Gentil que el siglo XVI no rompe con el XV, ni puede posicionarse antitéticamente con él, porque en muchos aspectos lo prologa ${ }^{54}$. En este sentido, conviene recordar que ya Santillana y Mena reflejan su aspiración a la fama a través de la escritura y, en particular, de la codificación amorosa. Por la estela que esta poesía del amor y la fama (de la fama por el amor) va dejando, como recuerda Vélez-Sániz, "Garcilaso compartirá con estos poetas el léxico del amor y de la fama, la relación amado/amada y la ansiedad de gloria eterna» ${ }^{55}$. ¿Acaso no percibió el Brocense esta contigüidad en las actitudes cuando, tras haber comentado a Garcilaso, decide hacer lo mismo con Juan de Mena? $\mathrm{Y}$ un segundo aspecto, entre más posibles; sabido es que, en el siglo XV, contienden en los círculos nobiliarios «las armas contra las letras», por decirlo con el título de un sugerente estudio de Peter E. Russell ${ }^{56}$; es asimismo bien conocido que Castiglione, en El cortesano, fustiga esta actitud. Cuando Garcilaso se autorrepresenta en la égloga III «tomando ora la espada, ora la pluma", no se limita a exponer el viejo topos de la fortitudo et sapientia, sino que hace «una declaración de que los otros nobles españoles, pocos, que durante más de un siglo antes que él habían defendido las letras tanto como las armas, estaban en lo correcto» ${ }^{57}$.

Vistas las cosas desde esta perspectiva, parece oportuno recordar lo que, con respecto a Juan de Mena, indicaba el maestro Sánchez de las Brozas al lector:

Es muy bien que este poeta sea tenido en mucha estima, aunque no fuera tan bueno como es por ser el primero, que sepamos, que aya illustrado la lengua castellana; aunque en Roma salió Virgilio y Horacio y otros de aquel siglo, nunca Ennio y Lucrecio y los muy antiguos dexaron de ser tenidos en gran veneración. Ansí que no ay razón para desechar a Juan de Mena porque en nuestra edad hayan salido otros de estilo muy diferente; antes este poeta ha de ser tenido en mucho porque le pueden leer todas edades y calidades de personas ${ }^{58}$.

54. Así lo expone, a grandes trazos, Pierre le Gentil, «Une fin et un commencement: Villon et les premiers humanistes», en La littérature française du Moyen Age, Paris, Armand Colin, 1968, págs. 179-186 ; de modo más pormenorizado, véase del mismo autor, Villon, París, Hatier, 1967.

55. Julio Vélez-Sainz, El Parnaso español: canon, mecenazgo y propaganda en la Poesía del Siglo de Oro, op. cit., pág. 55.

56. Peter E. Russell, «Las armas contra las letras: para una definición del humanismo español del siglo XV», en Temas de "La Celestina» y otros estudios, Barcelona, Ariel, 1978, págs. 207-239.

57. Id., pág. 236.

58. «El maestro Francisco Sánchez al lector», en Juan de Mena, Obra completa, 
Precisamente en esa edad del Prerrenacimiento, en ese afán por acercarse a los clásicos greco-latinos y a los grandes italianos del quattrocento con nuevas actitudes, incluso con toda la carga medievalizante que lastra su empeño; en esa edad en que se acusa la encrucijada cultural entre lo que persiste y lo que se vislumbra y en que se tantean nuevos caminos literarios; en esa edad y en ese estilo, precisamente, es donde conviene fundamentar la valoración de autores como Santillana y Mena. En este sentido, la voluntad de escalar a la cima parnasiana, y la consciencia de poder situarse en ella junto a los ya encumbrados, queda plasmada en los poemas que hemos ido mencionando $y$, particularmente, en las «coronaciones» dedicadas a Mosén Jordi por Santillana y al Marqués por Juan de Mena; y, más allá de los sujetos coronados, por efecto de la contigüidad entre el homo viator que transita por el poema y el poeta que lo sustenta, debe destacarse la autocanonización de los propios autores, del Marqués de Santillana y de Juan de Mena, que emprendieron la escalada a las cumbres parnasianas, con empeño tan novedoso como titubeante (sin duda titubeante por novedoso), por el camino de la escritura. Con ellos se inicia la formación del Parnaso español que se irá construyendo entre los siglos XV y XVIII con las carencias inaugurales inherentes, claro está, a cualquier construcción in fieri, como es el caso, de lo que ya Santillana era consciente en el Proemio al advertir -y asumir- que «de los primeros, primera es la especulaçión».

ed. Ángel Gómez Moreno y Teresa Jiménez Calvante, op. cit., pág. 9. 